\title{
Numerical Simulation and Optimization of Ventilation for Liquid Propellant Storehouse
}

\author{
Ningyuan Liu ${ }^{1, a}$, Cunyan Cui ${ }^{1, b}$, Tengda Xin ${ }^{1, c}$, Xiao Luan² \\ ${ }^{1}$ The Academy of Equipment, Beijing 101416, China, \\ ${ }^{2} 63618$ Troops of the People's Liberation Army, Korla 841001, China. \\ a2011jixie-Iny@alumni.sjtu.edu.cn, bccy6655@126.com, cxtd0701@126.com
}

Keywords: CFD, PPV, concentration field, propellant storehouse.

\begin{abstract}
To obtain the concentration field and the optimized ventilation mode of propellant storehouse, the thesis makes computational fluid dynamics (CFD) simulation to the storehouse with the boundary conditions and 3D models of original and optimization design. Positive pressure ventilation (PPV) is a successful tactic to bring down the high concentration of toxic gas, but it will lead to the expansion of toxic areas. To optimize the application of PPV in propellant storehouse, this paper investigates the impact of wind speed $(4-8 \mathrm{~m} / \mathrm{s})$ on concentration field using CFD method. According the results, an optimized ventilation mode of propellant storehouse is put forward.
\end{abstract}

\section{Introduction}

Toxic gas leakage in special fuel storehouse creates unique challenges to the safety of workers in the storehouse. When combined with flammable and explosive characteristics of the propellant, such leakage accidents are considered as the most destructive and dangerous accidents.

Unsymmetrical dimethyl-hydrazine (UDMH) is widely used in missile and aerospace test tasks as a kind of long-term storage propellant. In order to meet the needs of the test and combat missions, a certain amount of propellant must be stored for a long time in a special fuel storehouse. In the process of propellant storage and propellant loading, propellant tank cracks or perforation, pipeline corrosion aging, valve equipment failure, personnel misuse and other reasons will cause different degrees of propellant leakage. UDMH liquid leakage causes the formation of liquid pool on the ground, which volatilizes to gas and diffuses in the warehouse with a great risk.

Positive pressure ventilation (PPV) can drive away the toxic gas and heat, or prevent the toxic from gathering in the corner. In general, PPV can bring down the average concentration of toxic gas, but it will lead to the expansion of toxic areas [1]. To optimize the application of PPV in special fuel storehouse, this paper investigates the impact of wind speed $(4-8 \mathrm{~m} / \mathrm{s})$ on concentration field using CFD method.

\section{Modeling}

\subsection{Introduction to Simulation Method.}

Nowadays, thanks to the increasing CPU power the use of Computational Fluid Dynamics (CFD) is rapidly imposing also in the industrial risk assessment area, replacing integral models when particular situations, such as those involving indoor conditions, complex terrains and large obstacles, are involved [2]. Computational fluid dynamics (CFD) is a branch of fluid mechanics that uses numerical analysis and data structures to solve and analyze problems that involve fluid flows. Computers are used to perform the calculations required to simulate the interaction of liquids and gases with surfaces defined by boundary conditions [3]. With high-speed supercomputers, better solutions can be achieved. Ongoing research yields software that improves the accuracy and speed of complex simulation scenarios such as transonic or turbulent flows. Initial experimental validation of such software is performed using a wind tunnel with the final validation coming in full-scale testing, e.g. flight tests. 
The basic control equations for the leakage and diffusion process of dimethyl hydrazine in the storehouse are gas equation of state, fluid continuity equation, mass equation, momentum equation, energy equation and component transport equation. In the numerical calculation, the finite element method is used to calculate the unsteady state based on energy equation, spices transport equation and eddy dissipation model [4].

\subsection{Geometric model}

Based on the parameters of a UDMH storehouse, the geometric model is established. The basic parameters of the simplified geometric model are as follows: this is a $43 \times 18 \times 9$ meters kind of cuboid and the coordinate system is shown in Fig.1

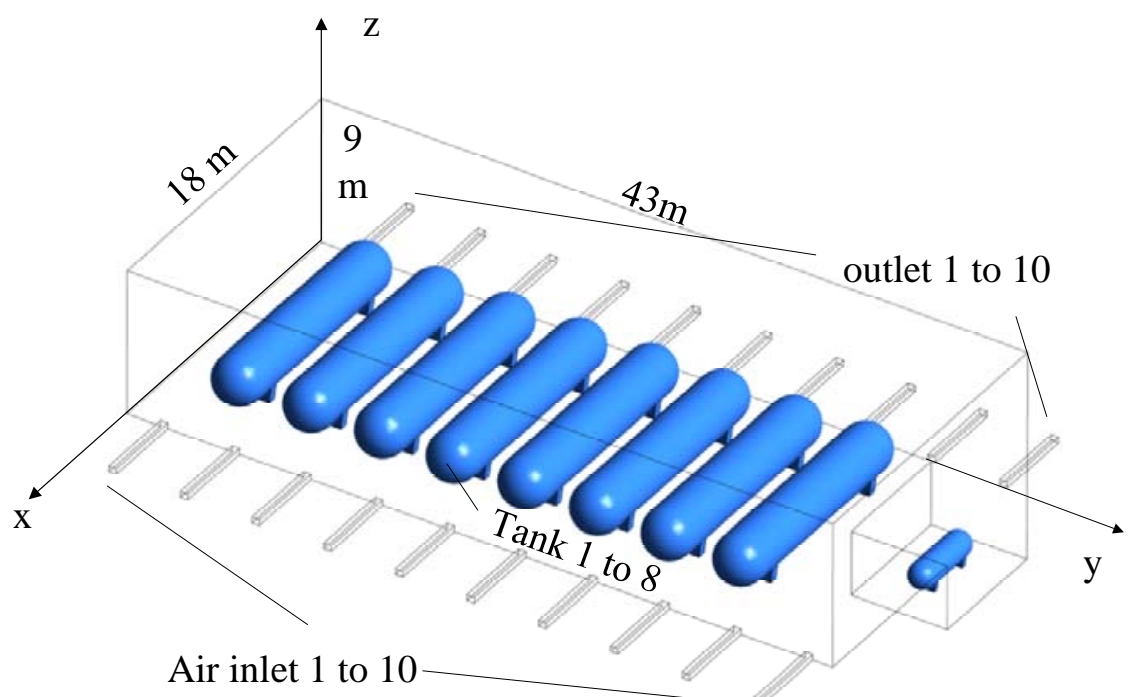

Fig.1 The Geometric model of storehouse

\subsection{Boundaries and Fundamental Assumptions}

In this case, the wind speed is $1 \mathrm{~m} / \mathrm{s}$, the temperature is $15^{\circ} \mathrm{C}$, and the relative humidity is $20 \%$. The leakage is between the tank 2 and the tank 3 and the coordinates is $(11,5)$.

Huang Zhiyong et al. conducted a related experimental study on the leakage problem of the liquid propellant storage. The results show that the evaporation rate of dimethyl hydrazine is mainly affected by factors such as liquid pool area, wind speed, temperature and humidity [5].

$$
v_{u}=2.6036 \mathrm{~A} \cdot 10^{-4} \gamma^{0.553}\left(0.001935 T^{2}+0.018988 T+0.51181\right) \cdot\left(-0.0002 H^{2}+0.0446 H-0.0265\right)
$$

$v_{\mathrm{u}}$ is the evaporation rate of dimethyl hydrazine, $\mathrm{mg} /\left(\mathrm{m}^{2} \cdot \mathrm{min}\right) ; A$ is the evaporation area, $\mathrm{m}^{2} ; \gamma$ is the evaporation surface wind speed, $\mathrm{m} / \mathrm{s} ; T$ is the ambient temperature, ${ }^{\circ} \mathrm{C} ; H$ is the relative humidity, \%.

According to the formula of UDMH evaporation rate, the evaporation rate per unit area of UDMH is $16.25 \mathrm{mg} /\left(\mathrm{m}^{2} \bullet \mathrm{min}\right)$ under these conditions. The density of UDMH is $0.7911 \mathrm{~g} / \mathrm{cm} 3$, after conversion, the pool evaporation rate per unit area is $1.224 \times 10^{-3} \mathrm{~m} / \mathrm{s} .1 .224 \times 10^{-3} \mathrm{~m} / \mathrm{s}$ is used as the speed of the leak inlet boundary conditions in the numerical simulation.

The boundary conditions used in the numerical simulation are shown in Table 1 . The wall is assumed to be adiabatic, no slip. The fluid area is incompressible, turbulent. The turbulence distribution is in accordance with the statistical law, which is in accordance with the Bernoulli hypothesis. Due to the limited space, it is assumed that the air distribution is uniform and stable, regardless of the stratification and stability of the air.

Table 1 Boundary conditions

\begin{tabular}{cccccc}
\hline Name & Type & Temperature(K) & Velocity(m/s) & Pressure $(\mathrm{atm})$ & spices \\
\hline Air inlet 1-10 & Velocity inlet & 288 & $4 / 6 / 8$ & 0.9 & Air \\
Air outlet 1-10 & Pressure outlet & 288 & - & 0.9 & Air/UDMH \\
Leak inlet & Velocity inlet & 288 & $1.224 \times 10-3$ & 0.9 & UDMH \\
Tank and wall & Wall & 288 & - & - & - \\
\hline
\end{tabular}




\section{Results and Discussion}

\subsection{Optimized Design of Ventilation.}

There are 12 air inlets and 7 outlets in the original storehouse, along the wall with average distribution. The main storage tanks in the warehouse are equally spaced in the middle of the storehouse. Considering the obstacle of the tanks, vents at intermediate of the gap between tanks will facilitate ventilation and gas UDMH exhausting. New design changes the number and location of the vents in the storehouse: set 10 air inlets, 10 outlets, corresponding to the inlet, outlet and the center of the gap between tanks.

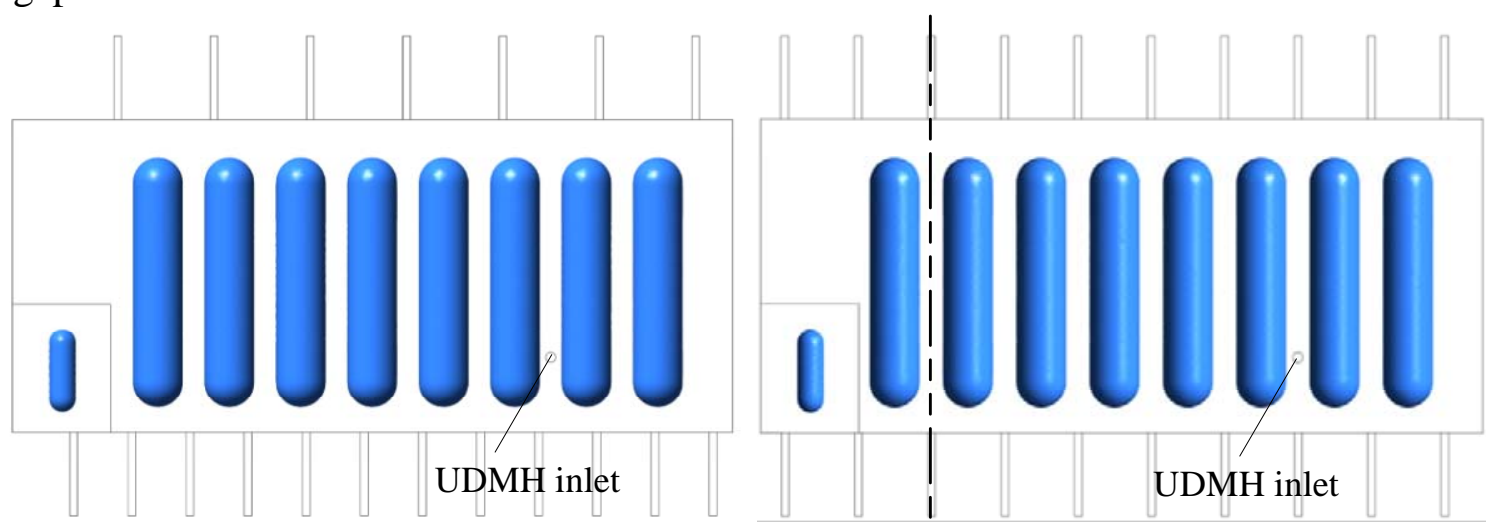

Fig.2 original ventilation design and optimized design

In order to verify the effect of the optimized design on the leakage of gas with the same location of optimized model and the original model are simulated and compared.

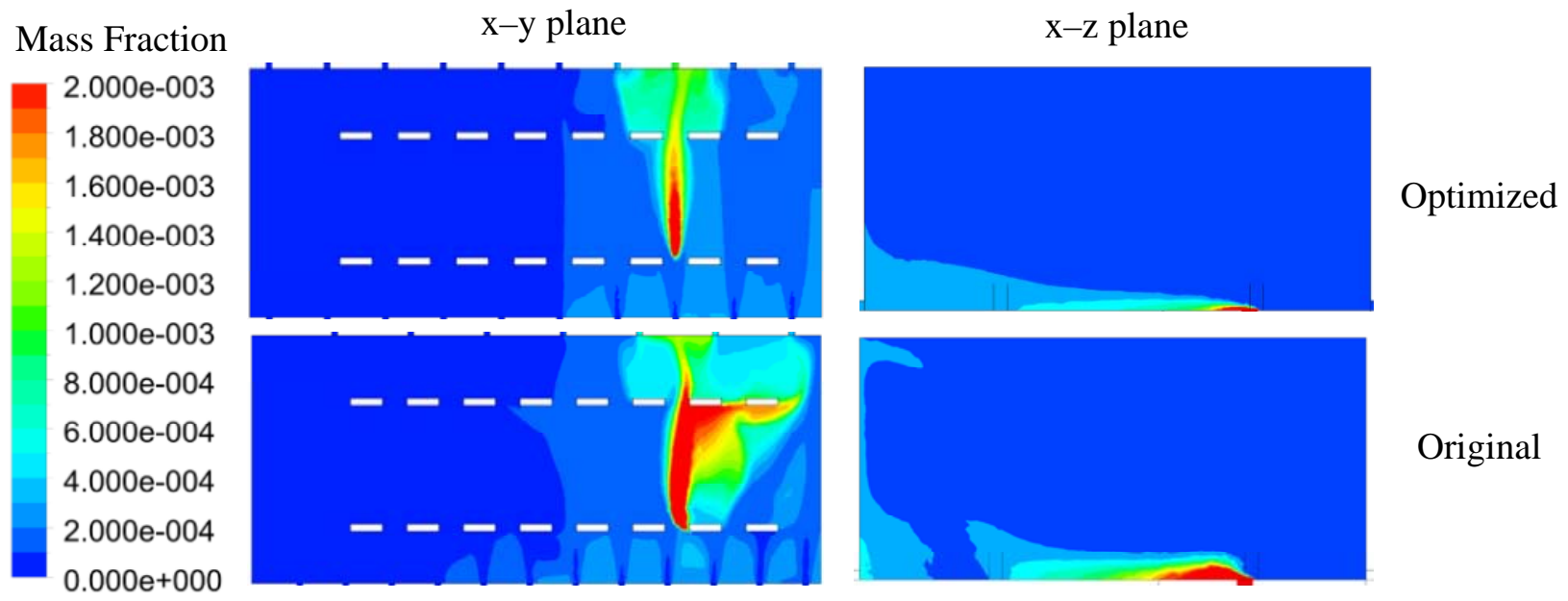

Fig.3 comparison between original ventilation design and optimized design

From Fig.3, the toxic range and concentration of UDMH in the optimized ventilation design are obviously smaller than those of the original design. From the simulation results we can see that it is necessary to optimize vents location based on tanks position, which is beneficial to the discharge of the leaking gas and the control of the toxic range.

\subsection{The Impact of Wind Speed}

Under the conditions of different inlet wind speed, the evaporation and diffusion of the dimethyl hydrazine liquid pool are simulated. According to the simulation results, the wind speed is analyzed from the diffusion range and the concentration distribution. Finally, the optimum positive wind speed is obtained based on the simulation results.

The simulation is mainly for the positive pressure ventilation wind speed, so the other conditions remain unchanged, respectively calculate the situation with the inlet air speed of $4 \mathrm{~m} / \mathrm{s}, 6 \mathrm{~m} / \mathrm{s}$ and $8 \mathrm{~m} / \mathrm{s}$. The simulation results are as follows: 


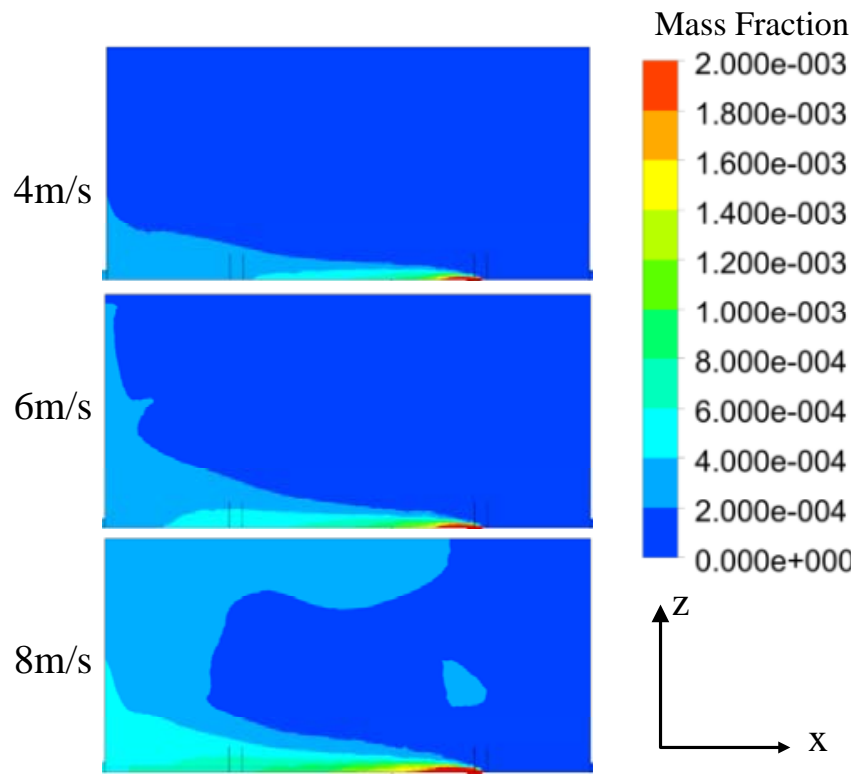

(a) $\mathrm{X}-\mathrm{z}$ plane concentration contour

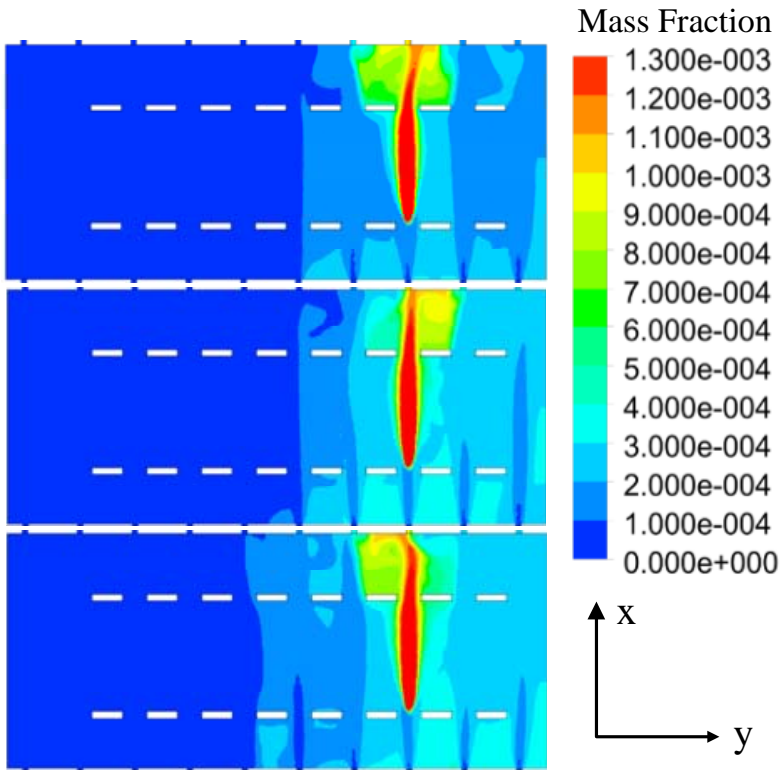

(b) $\mathrm{x}-\mathrm{y}$ plane concentration contour

Fig.4 concentration contour under different wind speed (600s)

Fig. 4 is the concentration contour under $4 \mathrm{~m} / \mathrm{s}, 6 \mathrm{~m} / \mathrm{s}$ and $8 \mathrm{~m} / \mathrm{s}$ after leaking for $10 \mathrm{~min}$. Fig.4(a) is the slice of $\mathrm{x}-\mathrm{z}$ plane and Fig.4(b) is $\mathrm{x}-\mathrm{y}$ plane. The exposure limit in 10min of UDMH is 100ppm [6], approximately equal to $2 \times 10^{-4}$ as mass fraction.

According to Fig.4(b), the toxic range (100ppm) of UDMH under the wind speed of $8 \mathrm{~m} / \mathrm{s}$ is larger than that of $6 \mathrm{~m} / \mathrm{s}$ and $4 \mathrm{~m} / \mathrm{s}$. The toxic range of $6 \mathrm{~m} / \mathrm{s}$ and $4 \mathrm{~m} / \mathrm{s}$ is almost the same, but the concentration over $3 \times 10^{-4}$ of $6 \mathrm{~m} / \mathrm{s}$ is larger while the higher concentration area over $6 \times 10^{-4}$ of $4 \mathrm{~m} / \mathrm{s}$ is larger. This results indicates that the increase of wind speed of PPV can reduce the size of the high concentration area and bring the concentration down. However, to some extent, it accelerate the diffusion and cause the range of low concentration $\left(<6 \times 10^{-4}\right)$ spread wider. Comparing the concentration distribution in Fig.4(a), the larger the wind speed, the greater the reflection effect of the wall surface, and the larger the toxic range in $\mathrm{x}-\mathrm{z}$ plane.

After a comprehensive comparison, in this case, the wind speed $6 \mathrm{~m} / \mathrm{s}$ is conducive to the rapid discharge of UDMH gas leakage, less toxic range, as well as bring down the concentration of high concentration areas.

\section{Conclusion}

For the optimization of ventilation for liquid propellant storehouse, CFD Simulations are performed with different wind speed and and different 3D models of storehouse. After comparison and analysis, the conclusions are as follows:

1) Optimized design of vents at intermediate of the gap between tanks facilitates ventilation and gas UDMH exhausting, its toxic range and concentration are smaller than the original design.

2) Positive pressure ventilation (PPV) is a successful tactic to bring down the high concentration of toxic gas, but fast wind speed will lead to the expansion of toxic range, strengthen the wall reflection and obstruction obstacles.

3) The wind speed $6 \mathrm{~m} / \mathrm{s}$ is conducive to the rapid discharge of UDMH gas leakage, less toxic range, as well as bring down the concentration of high concentration areas.

\section{References}

[1]. Prabodh Panindre, N.S.Susan Mousavi, Sunil KumarPositive. Pressure Ventilation for fighting wind-driven high-rise fires: Simulation-based analysis and optimization [J]. Fire Safety Journal, Vol. 87(2017), p. 57-64 
[2]. M. Pontiggia, M. Derudi, V. Busini, et al. Hazardous gas releases in urban areas: Assessment of consequences through CFD modelling [J]. Journal of Hazardous Materials, Vol. 171 (2009) No. 1-3, p. 231-236.

[3]. Information on: https://en.wikipedia.org/wiki/Computational_fluid_dynamics

[4]. Alberto Mazzoldi, Tim Hill b, Jeremy J. Colls. CFD and Gaussian atmospheric dispersion models: A comparison for leak from carbon dioxide transportation and storage facilities [J]. Atmospheric Environment, Vol. 42(2008), p.8046-8054.

[5]. Huang Zhiyong, Chen Xing, Ping Yanbing, et al. Evaporation characteristic of unsymmetrical dimethyl hydrazine propellant in storage [J]. Missile and Space Vehicles, (2011) No. 311, p. 5861.

[6]. Gao simi. Liquid Propellant [M]. Astronautic Publishing House, 1991. 